\title{
Uncertainty kills the long tail: demand concentration in peer-to-peer marketplaces
}

\author{
Karl Taeuscher ${ }^{1}$
}

Received: 26 March 2018 / Accepted: 17 February 2019 / Published online: 23 March 2019

(C) The Author(s) 2019

\begin{abstract}
Theory on the "Long tail effect" predicts that consumer demand in online markets spreads over a long tail of niche products. Recent research, however, provides opposing evidence and questions the theory's validity. In this paper, I aim to reconcile these opposing findings by proposing that consumer uncertainty represents a hidden yet important boundary condition for the long tail effect. Under high uncertainty, demand will be much more concentrated as consumers disproportionally choose the most reputable producers and products. I develop these arguments to predict the demand concentration in peer-to-peer marketplaces, a context in which consumers face high uncertainties about their transaction partners. Testing my predictions with a self-collected dataset of 862,755 transactions on a peer-to-peer marketplace for skillsharing supports my hypotheses. I find that a small share of producers disproportionately benefits from marketplace participation. During the observation period, twenty percent of producers generated $94 \%$ of sales. These findings suggest that an opposing rich-get-richer effect overrides the long tail effect in peer-to-peer marketplaces and other uncertain environments. I discuss how these findings inform research on peer-to-peer marketplaces and the sharing economy more broadly.
\end{abstract}

Keywords Multi-sided platforms $\cdot$ Peer-to-peer marketplaces $\cdot$ Long tail $\cdot$ Demand concentration $\cdot$ Uncertainty

JEL classification M13 New Firms · Startups · D8 Information, Knowledge, and Uncertainty

\section{Introduction}

Peer-to-peer marketplaces, an increasingly prevalent type of multi-sided platforms, change the way we live, work, and consume (Parker et al. 2016). The emergence of modern peer-topeer marketplaces (P2PMs) has enabled a variety of new markets, including accommodation sharing (e.g., Airbnb), ridesharing (e.g., Didi Chuxing), household services (e.g., TaskRabbit), self-made items (e.g., Etsy), and skillsharing (e.g., Udemy). Leading P2PM providers represent some of the

This article is part of the Topical Collection on Research Advances in Multi-Sided Platforms

Responsible Editor: Nizar Abdelkafi

Karl Taeuscher

karl.taeuscher@manchester.ac.uk

1 Present address: Innovation Management \& Policy (IMP), Alliance Manchester Business School, University of Manchester, Booth Street West, Manchester M15 6PB, United Kingdom highest-valued and fastest-growing private firms (CB Insights 2018) and substantially affect competition in their industries (e.g., Zervas et al. 2017). In the U.S. alone, consumers spend more than $\$ 60$ billion annually for services and products purchased through P2PMs (Colby and Bell 2016). By providing efficient access to large consumer markets, P2PMs have substantially reduced the barriers for individuals to participate as producers on these marketplaces (Einav et al. 2016). Given these multifold implications, P2PMs attract increasing attention from researchers across different fields (Casadesus-Masanell and Hervas-Drane 2010; Fraiberger and Sundararajan 2015; Hagiu and Wright 2015; Kyprianou 2017; Srinivasan and Venkatraman 2017; Täuscher and Laudien 2017).

In this paper, I use the increasingly prevalent context of P2PMs to advance understanding about consumer demand in online markets. In particular, I aim to contribute to theory on the long tail effect (Anderson 2004, 2006). In 2004, Chris Anderson observed that consumer demand in many internet markets is much less concentrated then in comparable offline markets. Advanced search and recommendation technologies substantially reduce consumers' search costs and, consequently, enable 
consumers to efficiently identify products that fit their unique preferences (Brynjolfsson et al. 2011; Hinz et al. 2010) and aggregated consumption choices will, therefore, become more diversified. Anderson thus predicted that sales distributions in internet markets would shift from the head of the curve (i.e., the most popular products) to the long tail of relatively obscure products. The long tail effect has spurred much interest in the academic literature and several studies provided empirical support for the effect (Brynjolfsson et al. 2011; Hinz et al. 2010; Kumar et al. 2014; Oestreicher-Singer and Sundararajan 2012a).

Some scholars, however, provide conflicting evidence and challenge the validity of the long tail effect (Elberse 2013; Tan et al. 2017). In fact, internet markets may engender rich-getricher effects that disproportionately benefit superstar producers and thus shift sales towards the head of the curve (Brynjolfsson et al. 2010). Because consumers have higher transparency about product information - including reputation signals such as customer reviews and ratings (Dellarocas 2005; Moreno and Terwiesch 2014) -, they can more easily identify the most popular products and will thus choose products that are already popular (Brynjolfsson et al. 2010). To date, these contradictory positions have not been reconciled.

In this article, I propose that consumer uncertainty provides an important boundary condition for the long tail and rich-getricher effects. P2PMs provide an insightful context to study the distribution of consumer demand under uncertainty. $\mathrm{P} 2 \mathrm{PMs}$ particularly differ from other providers - such as conventional online retailers (i.e., one-sided platforms) - in that consumers face strong uncertainties about their transaction partners (Pavlou and Gefen 2004). In P2PMs, producers are usually unknown to the public and lack access to traditional modes of quality signaling and trust-building ( $\mathrm{Ba}$ and Pavlou 2002). Due to the uncertainty about transaction partners, consumer in peer-to-peer marketplaces base their purchase decisions strongly on reputation signals like reviews (Einav et al. 2016). As a consequence, already popular producers will disproportionately grow their reputation and sales, while the long tail of products will remain unknown and without substantial sales. Hence, I propose that under high uncertainty, as in P2PMs, rich-get-richer effects will override long tail effects and thus lead to a highly concentrated demand distribution.

Testing my hypotheses with a dataset of 862,755 sales transactions on a leading P2PM for skillsharing strongly supports my arguments. I find that product sales are much more concentrated than in conventional ones-sided platforms like online retailers. In fact, sales are more concentrated than predicted by Pareto's $80 / 20$ distribution; a distribution that is commonly assumed for offline markets (Brynjolfsson et al. 2011). The sales distribution between individual producers is even more concentrated. Ten percent of producers account for $81 \%$ of sales, whereas $80 \%$ of all producers account for a combined sales share of less than $6 \%$. These findings suggest that P2PMs engender much stronger richget-richer than long tail effects.
The study theoretically and empirically advances research on consumer demand in online markets and peer-to-peer marketplaces. First, I contribute by uncovering an important contingency that can reconcile opposing findings in previous long tail studies (Brynjolfsson et al. 2011; Elberse and Oberholzer-Gee 2006; Hinz et al. 2010; Tan et al. 2017). Under high uncertainty, consumers will be disproportionally choose the small number of highly reputable producers and products. Differences in consumers' uncertainty can thus explain why some online markets do not exhibit a long tail effect but rather lead to rich-get- richer effects. Second, I contribute to the literature on peer-to-peer marketplaces and multi-sided platforms by empirical demonstrating the presence of rich-get-richer effects in P2PMs. In highlighting this effect, I draw attention to a self-reinforcing effect within marketplaces and platforms that complements the winner-take-all - a reinforcing effect at the level of platform marktets (Lee et al. 2006; Noe and Parker 2005; Schilling 2002; Sun and Tse 2007). Considering both self-reinforcing effects can advance theorization about the evolution of and competition between platform ecosystems (Tiwana et al. 2010; Tiwana 2015; Wessel et al. 2017).

From a practical perspective, these findings have important implications for policymakers because the long tail assumption plays a critical role in current discussions about the social and economic consequences of P2PMs. Several scholars, mostly discussing P2PMs under the labels of the sharing economy, ${ }^{1}$ have made the case that P2PMs lead to more equal and socially desirable forms of economic activity and work (for a good review, see Murillo et al. 2017). For instance, Sundararajan (2016) argues that these organizational forms have the potential to disrupt the traditional, corporation-centered model and can lead to the "end of employment and the rise of crowd-based capitalism" (Sundararajan 2016). Assuming that a long tail of participants will capture substantial benefits from participating in P2PMs will likely lead to different regulatory decisions than the assumption that a small number of superstar producers will capture an increasing share of revenues. Hence, my findings can also inform current policy debates on how to regulate P2PMs and the sharing economy.

\section{Theoretical background and hypotheses}

\section{Demand concentration in online markets}

For more than a decade, researchers in information systems, economics, and marketing have aimed to predict the distribution of demand (and subsequently sales) in online markets.

\footnotetext{
${ }^{1}$ Peer-to-peer marketplaces represent the central actors in the sharing economy, which is defined as the "web of markets in which individuals use various forms of compensation to transact the redistribution of and access to resources, mediated by a digital platform operated by an organization" (Mair and Reischauer 2017, p. 2).
} 
Driven by the rapid diffusion of internet-mediated forms of commerce, the related literature initially focused on how sales distributions of newly emerging online retailers (e.g., book sales on early Amazon ${ }^{2}$ ) differ from those of competing bricks-and-mortar retailers (e.g., book sales at Barnes and Noble). Sales distributions of bricks-and-mortar providers roughly follow the Pareto principle (Brynjolfsson et al. 2011). The principle, also known as $80 / 20$ rule, predicts that around $20 \%$ of products will account for around $80 \%$ of sales. Thus, related research often applies an 80/20 distribution as a benchmark for comparing sales distributions in online markets (Brynjolfsson et al. 2003; Brynjolfsson et al. 2006; Brynjolfsson et al. 2011). Chris Anderson's observation that sales of many online retailers were much less concentrated than the 80/20 distribution would suggest (Anderson 2006) caused subsequent research to explore the drivers behind this phenomenon (Brynjolfsson et al. 2006; Brynjolfsson et al. 2011; Hinz et al. 2010; Lee et al. 2011; Tan et al. 2017). Hinz et al. (2010) and Brynjolfsson et al. (2010) provide excellent reviews of these drivers.

A central explanation is that consumers' search costs determine the likelihood that they will encounter niche products that fit their specific preferences (Hinz et al. 2010). In comparison to shopping at bricks-and-mortar retailers (e.g., Barnes and Noble), consumers encounter much lower search costs when shopping at Amazon.com due to the online retailer's efficient search algorithm and hyperlinked recommendation systems (Oestreicher-Singer and Sundararajan 2012a, 2012b). When consumers can more easily identify niche products that fit their unique preferences, they are more likely to purchase such niche products. Demand thus shifts from few blockbuster products - the head of the demand curve - to the long tail of niche products (e.g., Brynjolfsson et al. 2010; Brynjolfsson et al. 2011; Hinz et al. 2010). Hence, sales will be less concentrated. Compared to the Pareto distribution, the long tail effect will lead to a more equally distributed distribution where the $20 \%$ most popular products (blockbusters) will account for less than $80 \%$ of sales. Various studies empirically confirmed that a reduction in search costs shifts demand towards the long tail (Brynjolfsson et al. 2011; Kumar et al. 2014; OestreicherSinger and Sundararajan 2012a; Tan et al. 2017; Zentner et al. 2013). For instance, a study by Brynjolfsson et al. (2011) showed that the $80 \%$ least-selling products of a fashion retailer's online channel accounted for almost half of the total sales $(47 \%)$ - significantly more than via the same retailer's catalog channel and the predicted the 80/20 distribution.

Several studies have, however, provided conflicting evidence and questioned the validity of the long tail hypothesis

\footnotetext{
$\overline{2}$ It is noteworthy that studies on Amazon.com generally took place before Amazon transformed itself into a third-party marketplace and a multi-business corporation (e.g., Brynjolfsson et al. 2006).
}

(Elberse 2013; Tan et al. 2017). These studies rather identified a rich-get-richer effect, also labeled as superstar effect (Brynjolfsson et al. 2010; Elberse and Oberholzer-Gee 2006), that shifts the demand curve in the opposing direction (Elberse 2013). Here, I use the term rich-get-richer effect to include dynamics at the level of products (the primary focus of previous research) and producers (for which I reserve the superstar label). The rich-get-richer effect describes the phenomenon that online markets may lead to an increase in demand concentration, where blockbuster products and superstar producers become even more popular over time (Elberse 2013). ${ }^{3}$ As a consequence, consumers may have incentives to choose a popular product over a niche product even when the niche product would better fit their personal preferences. Based on these arguments, the rich-get-richer effect can lead to demand distributions that are more concentrated than those of bricksand-mortar providers. Figure 1 graphically represents the opposing long tail and rich-get-richer effects on the sales distribution of products (or producers).

It is noteworthy that both the long tail effect and the richget-richer effect are further driven by supply-side dynamics (Brynjolfsson et al. 2010). The shift from bricks-and-mortar to online has substantially reduced retailers' costs for storing and offering products because online markets provide unlimited shelf-space and insignificant menu costs (Elberse and Oberholzer-Gee 2006). For information goods and other digitized products, there exist almost no storage and delivery costs (Bakos and Brynjolfsson 2000). The relatively low menu and storage costs thus incentivize online retailers to offer a large variety of niche products (Brynjolfsson et al. 2010; Brynjolfsson et al. 2011) that substantially exceeds the product variety offered in bricks-and-mortar retailers (Elberse and Oberholzer-Gee 2006). Some supply-side dynamics may, in turn, also support a stronger sales concentration. Online providers often compete in global markets that promise stronger economies of scale and economies of advertising (Brynjolfsson et al. 2010). This may incentivize retailers to focus only on a few blockbuster products and reduce their overall product variety (Brynjolfsson et al. 2010). As this study is concerned with the demand distribution - independent from changes in product variety - I primarily focus on demand-side arguments.

\section{Long tail and rich-get-richer effects in P2PMs}

P2PMs represent a form of multi-sided platforms, i.e., "interfaces-often embodied in products, services, or

\footnotetext{
${ }^{3}$ As the two effects have been conflated at times, it is important to distinguish between the rich-get-richer effect and the winner-take-all effect (Noe and Parker 2005). The winner-take-all effect describes the phenomenon that in some multi-sided platform markets, one platform will eventually dominate the market. In contrast to the rich-get-richer, the winner-takes-all effect primarily results from network effects (Sun and Tse 2007).
} 


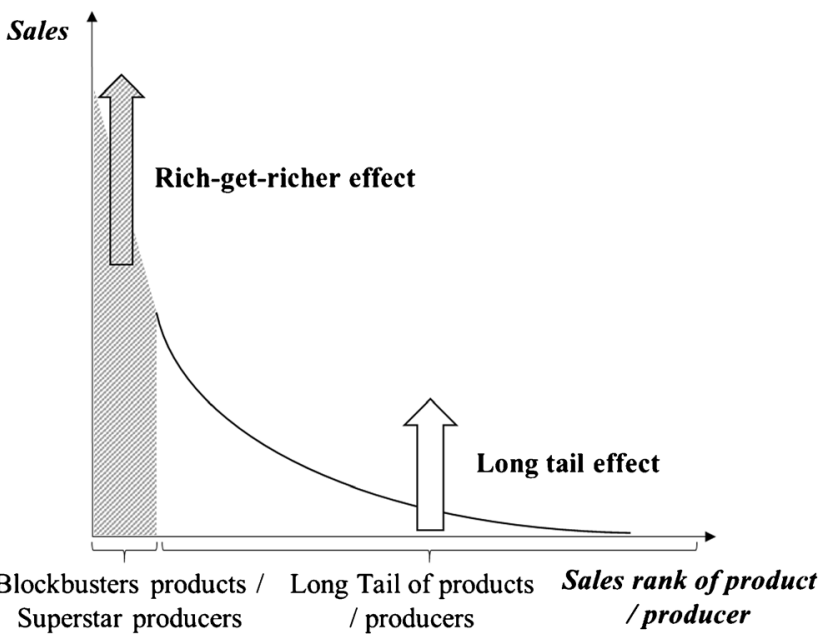

Fig. 1 Rich-get-richer and long tail effect

technologies - that can serve to mediate transactions between two or more sides, such as networks of buyers and sellers" (McIntyre and Srinivasan 2017, p. 143). P2PMs differ from other multi-sided platforms and online providers through their supply side participants. In P2PMs, the supply side primarily consists of individuals and small groups of individuals. While the long stream of research on physical goods marketplaces á la eBay labels this group as sellers (Hagiu and Wright 2015; e.g., Ye et al. 2014), this term is less inclusive for service marketplaces like Airbnb. Here, I use the term producers to refer to supply-side participants to acknowledge their commonality in producing some product or service. P2PMs further differ from some other types of multi-sided platforms in that they primarily refer to software-based interfaces such as mobile applications and websites. Hence, the conceptualization excludes both geographically bound marketplaces like shopping malls as well as marketplaces that are embedded in products and services that are primarily non-software based. As such, I define P2P marketplaces as software-based interfaces that mediate transactions between a demand side and supply side, where the supply side primarily consists of individuals or small groups of individuals.

In P2PMs, a particular challenge exists in that producers are generally unknown to the broader public and - by extension - unknown to demand-side participants. In contrast to mature and branded organizations, consumers cannot gather much information about individual producers via a Google search or their personal network. The less is publicly known about a transaction partner; the less can consumers engage in upfront inspection - a key mechanism to create trust (Einav et al. 2016). As consumers can access only limited information about the characteristics of the producers and products, they can assess certain characteristics only after the transaction occurred (Ba and Pavlou 2002; Pavlou and Gefen 2004). In addition, consumers in pure online markets cannot assess the trustworthiness of individuals through social cues such as body language (Pavlou and Gefen 2004). Moreover, as Einav et al. (2016, p. 617) articulate, "it does not take a PhD in economics to see the potential incentive problems in semianonymous online transactions," and some empirical evidence shows that producers in P2PMs may exploit these information asymmetries by misrepresenting the quality of their products (Jin and Kato 2006; Lewis 2011).

Consumers thus face important uncertainty about the quality and trustworthiness of producers due to information asymmetries between transaction partners (Erdem and Keane 1996; Shulman et al. 2015). Uncertainty refers to individuals' inability to predict the probability of specific outcomes (Santos and Eisenhardt 2009). For consumers in P2PMs, the outcome of interest likely relates to their ex-post satisfaction with their purchase decision. This may reduce consumers' satisfaction considerably if, for instance, the quality of the purchased product is poor, the producer did not deliver the product as promised, or the producer cancels the transaction. As uncertainty affects market behavior (Erdem and Keane 1996; Podolny 1994; Shulman et al. 2015; Townsend et al. 2018), I expect that the relatively high uncertainty in P2PMs will affect consumers' demand and purchase decisions.

If consumers' uncertainty about transaction partners is high, they will pay greater attention to cues and signals about the reputation of transaction partners. Reputation refers to a judgment about producers' or products' perceived quality (i.e., "being good") or prominence (i.e., "being known") (Rindova et al. 2005). In online markets, standardized customer review systems provide the central source of reputation signaling (Bajari et al. 2003; Cabral and Hortaçsu 2010; Dellarocas 2005; Moreno and Terwiesch 2014; Resnick et al. 2006). Consumers are more likely to attend to and select products that they perceive to be more prominent and popular. For instance, consumers are much more likely to choose books that are presented as bestsellers (Bikhchandani et al. 1998). In online markets, there exists long evidence that a product's review volume acts as reputation mechanism and drives consumers' purchase decisions (for a good review, see Floyd et al. 2014). In P2PMs, these reputation signals are particularly important because individual producers generally lack access to other reputation or status signals, such as affiliations with high-status organizations (Reuber and Fischer 2005; Rindova et al. 2007). As consumers of P2PMs are more likely to select products with a larger review volumen, such products will be chosen more frequently, and will subsequently gather more reviews. Due to this selfreinforcing effect, initial popularity will thus amplify over time and engender a strong rich-get-richer effect.

As P2PMs are aware of consumers' preference for already popular products, they may amplify the rich-get-richer effect through the calibration of their search and recommendation algorithms. For instance, online providers may use prducts' review volume as a central data point in their recommender systems, i.e. algorithms that determine the rank order of 
recommendations (Fleder and Hosanagar 2009). While the search and recommendation algorithms of P2PMs likely help consumers to find niche products that fit their preferences - as argued in the long tail literature - such algorithms can thus increase the relative popularity of blockbuster products and superstar producers. Based on these arguments, I expect that the demand distribution in P2PMs is more concentrated than for conventional online retailers.

To increase the precision of my predictions, I focus specifically on peer-to-peer marketplaces for skillsharing (subsequent: skillsharing marketplaces). In skillsharing marketplaces, producers (partly) digitize their knowledge and skills in the form of online courses, tutorials, digital designs, or other information products. As with other information goods, consumers can only evaluate the quality of these products after consuming them and thus make their purchase decisions under substantial uncertainty (Basuroy et al. 2006; Reinstein and Snyder 2005). This product-related adds to the previously outlined uncertainty related to producers in P2PMs. Markets for information goods are further characterized by the potential for geographically distant transaction partners as transactions occur via digital channels. As such, transaction partners generally do not interact in person and sales are less affected by local regulations and other environmental factors. Skillsharing thus provides a seemingly robust context to study the long tail under high consumer uncertainty.

For the lack of a clear benchmark, I use the Pareto distribution $(80 / 20)$ as a benchmark. Existing studies have shown that the demand distributions are less concentrated in online providers (Brynjolfsson et al. 2011; Kumar et al. 2014; Oestreicher-Singer and Sundararajan 2012a; Tan et al. 2017; Zentner et al. 2013) - the $80 / 20$ distribution thus presents a very conservative benchmark:

Hypothesis 1: Consumer demand in skillsharing marketplaces is highly concentrated in the head of the demand curve. Twenty percent of products will account for more than $80 \%$ of sales.

The above-presented arguments will affect the demand concentration at both the level of producers and products. Reviews for a producer's other products will serve as signals about a producer's overall reputation (Wessel et al. 2017). Even when a product is new and has not yielded many reviews yet, consumers may therefore face lower uncertainty when the product is offered by a producer who has already gathered many reviews for other products. Hence, consumers will more likely choose products from producers with many overall reviews across their products. As such, the rich-get-richer effect will become stronger at the level of producers, where the prominence of one product can reduce consumers' uncertainty about other products by the same producer. Thus, I hypothesize:
Hypothesis 2: In skillsharing marketplaces, consumer demand is more concentrated at the producer-level than at the product-level.

\section{Research methodology}

\section{Empirical context and dataset construction}

I test these hypotheses with data from a leading peer-to-peer marketplace in which individuals create and sell short online courses. At the time of analysis, the marketplaces claims to serve more than 10 million learners. Individual producers use the P2PM to create video-based online courses on any subject of their interest and expertise. Courses cover a broad spectrum of learning categories - including business, programming, and languages. The skillsharing marketplace's customers are primarily adult learners who aim to advance their professional skills or improve in their field of interest. Everybody can become a 'producer' on the marketplace by creating and offering an online course via the digital platform on which the marketplace is hosted. Producers only need to comply with a set of general guidelines but are not restricted to the type and number of courses they offer. As such, various producers offer competing courses on topics that are seemingly in-demand (e.g. introductory courses for programming languages).

Consumers only need to register and set up a profile to participate in the marketplace. After they purchase a course from one of the producers, they have full access to its included materials (videos, text files, presentations, etc.). Courses remain available in a personalized cloud-based library. To watch the videos and engage in additional multi-media material provided by a course, learners can use a web-based or mobile platform to access the marketplace and their purchased content. Also, they can interact with other learners in coursespecific discussion forums. Customers are asked to provide an online rating after they have shown a minimal degree of engagement with the content of a course. The marketplace provider employs a commission fee-based revenue model by capturing a share of each course sale.

I use scraped data from the marketplace's website. The marketplace represents each course on a separate web page. Each course page features a short description of the course and the producers, the number of enrolled students, the length of the course, the number of lectures in the course, and the number and content of previous user reviews. To ensure data consistency and to isolate the effects of interest, I only focus on courses that are offered in the English language (representing around $85 \%$ of all courses on the marketplace at the time). Initial data collection was executed in December 2015. After eliminating courses with missing data, I ended up with a panel of 11,854 courses. For the purpose of the analysis, I captured 
data for these courses during a three-month observation in the first quarter of 2016. I expected a three-month period to be sufficient to capture meaningful changes in a rapidly growing marketplace. At the same time, the relatively short time frame allowed me to minimize potential effects in the broader market environment (e.g., changing regulations) and specific marketplace (e.g., changes of business model or search algorithm). ${ }^{4}$

Research primarily measures the long tail through its absolute tail length (number of products) or relative tail distribution (for a review of these approaches, see Brynjolfsson et al. 2010). Relative long tail measures focus on the relative share of demand below and above a certain sales rank (e.g., sales share for the $20 \%$ best-selling products). While the absolute length allows comparing supply-side effects in the move from bricks-and-mortar to online retail in established markets, it is a less useful measure in growing markets (Tan et al. 2017). In turn, scale-invariant relative approaches allow for better comparison between studies in different markets and provide more meaningful findings in the absence of a clear offline competitor. As the study is primarily concerned with how sales distributions change over the three-month period, I do not include producers and products that entered the marketplace during the observation period. In other words, all courses included in the panel were already offered before the start of the observation period. Including these late-entrants would likely shift the sales distribution more strongly towards the relative head of the curve (e.g., 10\% of top-selling products) because a larger share of courses would yield none or very few sales due to their late entrance.

To calculate sales units during the observation period, I make use of the fact that (a) each profile page indicates the total number of enrolled students and (b) that users have no incentives to 'leave' a course once they have purchased it. The marketplace provider offers customers unlimited storage space of course content in their cloud-based course libraries. Similar to e-books purchased in online libraries, users will unlikely abandon them entirely but rather choose not to use them (e.g., after finishing the course) but keep them for later reference or for the lack of incentives to do otherwise. This allows me to infer the number of product sales from in a period (sales) by subtracting the number of enrolled students at the end of the observation period from the number of enrolled students at the beginning of the period. I decided to use the number of unit sales, rather than considering differences in nominal prices because the marketplace provider frequently offers courses at a highly discounted price (e.g., each course for \$19). Hence, the listed course prices seemed to be an

\footnotetext{
${ }^{4}$ I closely monitored market-related news and press releases by the marketplace provider and its competitors to ensure that no meaningful changes did occurr during the observation period. The qualitative data collection was part of an in-depth case of the marketplace provider, in which I conducted interviews with its executives, lead investor, and managers of competing skillsharing marketplaces.
}

unreliable measure for actual course prices. A total of 862,755 sales transaction occurred during the observation period in the selected panel. To test the distribution at the level of producers, I subsequently aggregated the data at the level of producers. While many producers offer only one (4371) or two courses (1139), the five most active producers offer more than 100 courses each (median: 4).

\section{Results}

Hypotheses 1 stated that sales are more concentrated than a Pareto distribution would suggest. Table 1 presents sales during the observation period at the product-level (first four columns) and the level of producers (remaining columns), grouped into sales-rank percentiles. The first row presents the sales share of the $5 \%$ least successful products and producers, the 80 percentile represents the accumulated sales share of the bottom $80 \%$, and the 95 percentile (last row) presents the sales share of the $95 \%$ least successful products and producers. The table shows that around $15 \%$ of products and $5 \%$ of producers do not account for any sales during the observation period. The rounded sales shares for subsequent percentiles suggest that the bottom $30 \%$ of producers account for less than $0.1 \%$ of sales. Focusing on top sellers, the last row thus indicates that $5 \%$ of products account for more than one-third of sales. The 80 percentile shows that product-level sales are slightly more concentrated than a standard $80 / 20$ distribution, as $20 \%$ of products account for $82.4 \%$ of sales. The table further presents confidence intervals for the values. They suggest that the sales share of the long tail $(80 \%$ lowselling products) is significantly below the $20 \%$ mark (at a 95\% confidence interval). This supports hypothesis 1.

Hypothesis 2 stated that producer-level sales will be more concentrated than product-level sales. The right-hand side of Table 1 shows that producer-level sales are much more concentrated and head-heavy. The curve shows that $80 \%$ of producers account only for $5.8 \%$ of sales, while the $5 \%(10 \%)$ most successful producers generate $65.5 \%(81.1 \%)$ of sales. The bottom $50 \%$ of producers account for only $0,3 \%$ of sales, compared to the sales share of $1.9 \%$ of the $50 \%$ less popular products. These metrics show a much higher concentration at the level of producers and thus support hypothesis 2 .

The percentile values allow calculating Gini coefficients and visualizing the distribution with Lorenz curves. The Gini coefficient and Lorenz curves are common tools in economics to describe degrees of (in)equality and are commonly used to represent sales distributions in the long tail literature (Brynjolfsson et al. 2011; Elberse and Oberholzer-Gee 2006). Intuitively, a point on the Lorenz curve quantifies the proportion of cumulated sales of a percentile $\mathrm{x}$ of the entire population's sales. Lorenz curves typically display the population's percentiles on the horizontal axis and the cumulated distribution on the vertical axis. The curves are produced with the 
Table 1 Sales distribution for products and producers

\begin{tabular}{|c|c|c|c|c|c|c|c|c|}
\hline \multirow[t]{2}{*}{ Percentile } & \multicolumn{4}{|c|}{ Sales distribution at product-level } & \multicolumn{4}{|c|}{ Sales distribution at producer-level } \\
\hline & Coef. & Std. Err. & $95 \% \mathrm{C}$ & Interval & Coef. & Std. Err. & $95 \%$ & Interval \\
\hline 0 & 0 & & & & 0 & & & \\
\hline 5 & 0 & & & & 0 & & & \\
\hline 10 & 0 & & & & 0.000 & 0.000 & 0.000 & 0.000 \\
\hline 15 & 0.000 & 0.000 & 0.000 & 0.000 & 0.000 & 0.000 & 0.000 & 0.000 \\
\hline 20 & 0.001 & 0.000 & 0.001 & 0.001 & 0.000 & 0.000 & 0.000 & 0.000 \\
\hline 25 & 0.002 & 0.000 & 0.002 & 0.002 & 0.000 & 0.000 & 0.000 & 0.000 \\
\hline 30 & 0.003 & 0.000 & 0.003 & 0.004 & 0.000 & 0.000 & 0.000 & 0.000 \\
\hline 35 & 0.006 & 0.000 & 0.005 & 0.006 & 0.001 & 0.000 & 0.001 & 0.001 \\
\hline 40 & 0.009 & 0.000 & 0.008 & 0.009 & 0.001 & 0.000 & 0.001 & 0.001 \\
\hline 45 & 0.013 & 0.000 & 0.013 & 0.014 & 0.002 & 0.000 & 0.002 & 0.002 \\
\hline 50 & 0.019 & 0.001 & 0.018 & 0.020 & 0.003 & 0.000 & 0.002 & 0.003 \\
\hline 55 & 0.028 & 0.001 & 0.027 & 0.029 & 0.004 & 0.000 & 0.003 & 0.004 \\
\hline 60 & 0.040 & 0.001 & 0.038 & 0.041 & 0.006 & 0.000 & 0.005 & 0.006 \\
\hline 65 & 0.056 & 0.001 & 0.054 & 0.058 & 0.009 & 0.001 & 0.008 & 0.010 \\
\hline 70 & 0.080 & 0.002 & 0.077 & 0.084 & 0.016 & 0.001 & 0.014 & 0.018 \\
\hline 75 & 0.117 & 0.002 & 0.113 & 0.122 & 0.031 & 0.002 & 0.027 & 0.034 \\
\hline 80 & 0.176 & 0.003 & 0.169 & 0.183 & 0.058 & 0.003 & 0.052 & 0.065 \\
\hline 85 & 0.269 & 0.004 & 0.260 & 0.277 & 0.108 & 0.005 & 0.097 & 0.118 \\
\hline 90 & 0.415 & 0.005 & 0.405 & 0.425 & 0.189 & 0.008 & 0.173 & 0.205 \\
\hline 95 & 0.645 & 0.004 & 0.636 & 0.653 & 0.345 & 0.013 & 0.321 & 0.370 \\
\hline
\end{tabular}

Lorenz command (Jann 2016) in STATA 14.2. In addition to the main measure of sales, they further represent the distribution of all sales until the beginning of the observation period (total sales). This allows gaining some insights into how the distribution might change over time. Figure 2 presents the Lorenz curves at the product-level (left) and producer-level (right). The comparison conveys that new sales are more concentrated, both at the level of products (left) and producers (right). This finding suggests that sales distribution might become more concentrated over time.

Gini coefficients support this assumption. Productlevel sales (Gini coeff. $=0.765)$ are less concentrated than producer-level sales (0.859). Both metrics indicate a higher concentration in sales during the observation period, compared with total sales of products (0.719) and producers (0.859) up until the beginning of the observation period. Comparing the distributional statistics to previous findings facilitates their interpretation. For instance, Brynjolfsson et al.'s (2011) study of a multi-channel retailer revealed much lower sales concentration in their online channel (Gini coeff. $=0.49$ ) as well as their catalog-based offline channel (0.53). Hinz et al. (2010) study sales distribution of a video-ondemand provider and find a mean Gini coefficient of 0.63 . The combined findings suggest that P2PMs for skillsharing show a much more concentrated sales distribution than one-sided online retailers. Further, they suggest that that producer-level sales are more concentrated than product-level sales and that distributions likely become more concentrated over time.
Fig. 2 Distribution of sales until (dark red) and during the observation period (blue)
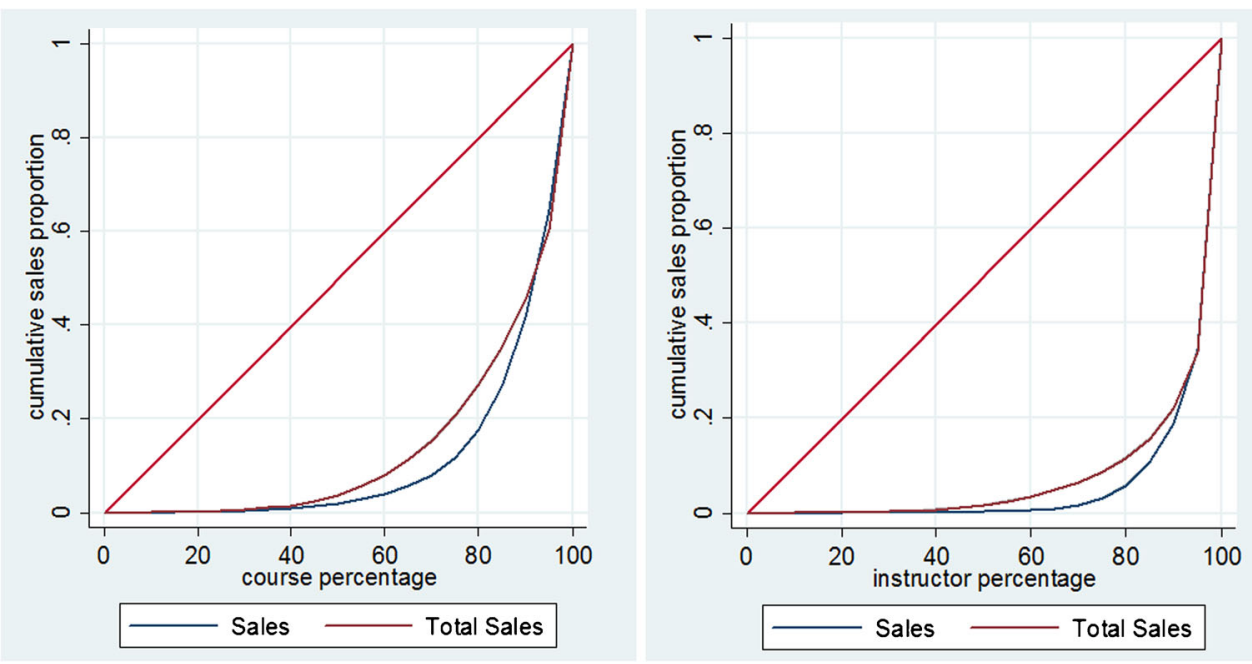


\section{Discussion}

\section{Generalizability of findings}

I hypothesized about the demand distribution in skillsharing marketplaces but the findings can inform P2PMs in general. I argued that P2PMs commonly differ from online retailers in that producers are individuals that lack access to traditional reputation signals. As this condition is a main driver of consumers' uncertainty, I expect that rich-get-richer effects will also occur in other types of P2PMs. I further discussed three conditions that characterize skillsharing marketplaces as the study's empirical context: an inability to evaluate product quality ex-ante, low rivalry in product usage, and global competition between products. Skillsharing marketplaces may (partly) differ in these conditions from other P2PMs (e.g., Airbnb, Uber) and, therefore, exhibit higher stronger economies of scale and competitive behavior from producers. Other P2PMs - which lack these conditions - may thus demonstrate weaker rich-get-richer effects than skillsharing marketplaces. Hence, the findings will be most similar in P2PMs for other information goods, such as marketplaces for apps, music, images, or digital designs.

\section{Implications}

This research contributes to the broader literature on demand distributions in online markets (Brynjolfsson et al. 2011; Hinz et al. 2010; Kumar et al. 2014; Oestreicher-Singer and Sundararajan 2012a; Tan et al. 2017). The main contribution of this article is that consumer uncertainty presents an important boundary condition for the long tail and rich-get-richer effect. When consumer uncertainty is high - such as in the context of $\mathrm{P} 2 \mathrm{PMs}$ - consumers aim to reduce their uncertainty by transacting with producers with high reputation in the marketplace. As such, they prefer products by reputable producers over products that would fit their personal preferences more strongly. In P2PMs, consumers thus strongly rely on reputation signals such as review volume (Einav et al. 2016; Fradkin 2017). I proposed that uncertainty disproportionately favours reputable producers and products and consequently leads to highly concentrated sales distributions. Uncovering consumer uncertainty as a main boundary condition for the long tail effect allows future research to predict more accurately when and where to expect long tail or rich-get-richer effects. Among others, the uncertainty criterion suggests that long tail effects will be weaker in newly emerging markets, where consumers generally face strong uncertainties about producers' and products' unobservable quality (Navis and Glynn 2010). In uncovering this important boundary condition, this study adds to the scarce literature that challenges the general validity of long tail dynamics in online markets (Elberse 2013; Elberse and Oberholzer-Gee 2006; Tan et al. 2017).
The findings theoretically and empirically inform the literature on peer-to-peer marketplaces (Hagiu and Wright 2015; Kyprianou 2017; Moreno and Terwiesch 2014; Srinivasan and Venkatraman 2017; Täuscher and Laudien 2017). The study suggests that while P2PMs share many technological and demand-side characteristics with conventional (onesided) online platforms, existing theories may not be suited to explain the specific dynamics of P2PMs. The high uncertainty about transaction partners might lead to significantly distinctive consumer behavior in P2PMs. This matters as research on multi-sided platforms generally assumes that network effects represent a central driver of platform's attractiveness and value creation (e.g., Shankar and Bayus 2003). Based on this assumption, P2PM providers have a clear incentive to maximize the number of producers and products on their platform (Zhu and Iansiti 2012). To attract and retain a large number of producers and products requires P2PMs to offer a certain level of value to these producers. As producers in many $\mathrm{P} 2 \mathrm{PMs}$ derive value primarily from the opportunity to generate revenues, the P2PM's value to the majority of producers may substantially decrease if a small share of producers accounts for most sales. The rich-get-richer effect can thus threaten the P2PM's competitiveness in the markets for producers and consumers. A more nuanced understanding of these marketplace dynamics can guide research on platform openness, pricing and advertising decisions, or the calibration of search and recommendation algorithms (Fleder and Hosanagar 2009; Jiang and Tian 2016; Tan et al. 2017).

The findings have direct managerial implications as they sensitize entrepreneurs and managers to these dynamics. Sales opportunities may become increasingly captured by a small number of reputable actors and these actors will, in turn, gain relative market power. Managers of P2PMs should thus take into account that attracting and retaining a long tail of lowselling producers and niche products may not only provide an important competitive factor but (Hagiu and Wright 2015) but may secure the provider's relative power position against individual producers. Marketplace managers should thus monitor and proactively address these dynamics.

The study further informs theoretical and practice-oriented discussions regarding socio-economic consequences of P2PMs. Social and economic implications of P2PMs are an increasingly prevalent theme, particularly in the sharing economy literature (Dreyer et al. 2017; Heinrichs 2013; Mair and Reischauer 2017; Murillo et al. 2017; Puschmann and Alt 2016). P2PMs arguably represent the central actors and drivers of the sharing economy. Hence, there exists strong interest in how P2PMs will affect broader changes regarding the nature of work and employment, the structure of markets, and economic activity in general (Belk 2014; Dreyer et al. 2017; Dyal-Chand 2015; Heinrichs 2013; Martin 2016; Schor 2014). The related literature has primarily highlighted implications that are socially desirable. For instance, 
Sundararajan (2016) proposes that the sharing economy can lead from a corporation-centered economic model towards a system of 'crowd-based capitalism.' As low transaction costs reduce the need to organize work in traditional corporations (Henten and Windekilde 2016), individuals can organize in less hierarchical forms of work (Laloux 2014). My findings partly challenge such an optimistic perspective as the rich-getricher effect may threaten the social desirability of platformbased work for the majority of participating producers. The study provides first evidence that P2PMs might lead to new hierarchies, where most of the value will be captured by a small share of individuals.

Making theoretically and empirically grounded predictions about the socio-economic implications of P2PMs can have important implications for policymakers. P2PMs have gained socio-economic importance because an increasing number of individuals earns their primary income through their marketplace activities (Spreitzer et al. 2017). This matters as, for instance, different P2PMs currently face lawsuits to formally recognize full-time producers as their employees (Ben-Shahar 2017). Hence, the ability and willingness of P2PMs to sustain fair and equal opportunities for its producer network may become socially and politically desirable. This provides an important area for practice-relevant research, as law- and policymakers still lack reliable evidence about the multifold consequences of these new forms of quasi-employment. For P2PMs to provide such equal and distributed income opportunities, policymakers may need to develop taxation and regulation schemes that distinguish between superstar producers and the long tail of less successful producers. A differentiated regulation and taxation approach could limit the predicted rich-get-richer effects to a certain degree. This study thus provides a starting point for a more evidence-based discussion of the sharing economy's socio-economic implications.

\section{Limitations and future research}

The study is not without limitations. One limitation relates to the novelty of the study's context and the related difficulties in using longitudinal data. As discussed, a longer time frame could have introduced a substantial bias due to the rapidly changing nature of the platform (including its policies) and market. Future studies of skillsharing marketplaces can draw on more longitudinal data as these marketplaces mature and provide present more stable market contexts. Further research opportunities result from my decision to focus on demandside effects. Studies focusing on supply-side mechanisms of the long tail effect could complement this study and focus on the shift in the absolute tail length over time (Brynjolfsson et al. 2010). While some researchers make a case for including changes in the absolute tail length (e.g., Hinz et al. 2010), the decision to isolate demand-side effects from supply-side changes provides a conservative approach in light of my hypotheses. Including the additionally added products during the observation period would technically increase the relative share of blockbuster products and superstar producers.

Future research could complement the chosen demand-side perspective with perspectives that focus on the agentic behavior of P2PMs. As multi-sided platforms have clear incentives to increase new network size (McIntyre and Srinivasan 2017), they may actively promote new market entrants and less popular products to counter-balance the rich-get-richer effect and provide continued value to less popular producers (Rietveld et al. 2017). Future research could study how certain platform strategies and policy changes can attenuate the rich-get-richer effect in P2PMs.

There exist further research opportunities in studying how producers' strategic behavior effect sales distributions in P2PMs. Increased competition between a large network of producers may incentivize producers to develop distinctive positions in the consumer space (Porter 2001). For instance, a recent study by Wessel et al. (2017) proposes that lateentrants in P2PMs may actively differentiate their offerings to overcome the disadvantage of arriving late to the market. Such a purposeful differentiation may further increase product variety and strengthen the long tail effect. In the presence of strong negative same-side network effects (between producers), less popular producers may also choose to cease their participation in a P2PM when the network of producers has surpassed a certain threshold (Boudreau and Jeppesen 2015). Future research could thus study how producers' strategic behavior affects sales distributions in P2PMs.

\section{Conclusion}

For over a decade, academic research and practitioners have suggested that online markets will decrease the concentration of consumer demand - best encapsulated by the title "Goodbye Pareto Principle, Hello Long Tail" (Brynjolfsson et al. 2011). Recent empirical findings, however, challenge the long tail theory (Tan et al. 2017). I aimed to reconcile these contradictory findings by proposing that consumer uncertainty presents a critical contingency for the long tail effect. Heterogeneity in the degree of consumer uncertainty can explain why some study contexts experience long tail effects, while others experience a shift toward the head of the distribution curve. This theoretical proposition guided an empirical investigation of the demand concentration in peer-to-peer marketplaces - an embodiment of high consumer uncertainty. Based on these arguments, I hypothesized that demand concentration in skillsharing marketplaces - a popular form of peer-to-peer marketplaces - would be more concentrated than a common distribution curve would suggest. My study of 862,755 sales transactions on a leading skillsharing marketplace provides strong support for this hypothesis and the 
underlying theory. I find that the sales distribution in skillsharing marketplaces is significantly more head-heavy and concentrated than sales for comparable experience goods in one-sided retailers - both online and offline. As predicted, I further find that sales are significantly more unequally distributed between producers: $20 \%$ of producers account for $94 \%$ of sales. These findings provide strong support that rich-getricher effects override long tail effects under high consumer uncertainty.

Open Access This article is distributed under the terms of the Creative Commons Attribution 4.0 International License (http:// creativecommons.org/licenses/by/4.0/), which permits unrestricted use, distribution, and reproduction in any medium, provided you give appropriate credit to the original author(s) and the source, provide a link to the Creative Commons license, and indicate if changes were made.

\section{References}

Anderson, C. (2004). The Long Tail, 12(10), 170-177. Retrieved from https://www.wired.com/2004/10/tail/. Accessed 10 Apr 2017.

Anderson, C. (2006). The long tail: How endless choice is creating umlimited demand. London: Random House.

Ba, S., \& Pavlou, P. A. (2002). Evidence of the effect of trust building Technology in Electronic Markets: Price premiums and buyer behavior. MIS Quarterly, 26(3), 243. https://doi.org/10.2307/4132332.

Bajari, P., Hortaçsu, A., \& Hortacsu, A. (2003). The Winner's curse, reserve prices, and endogenous entry: Empirical Insights from eBay auctions. The Rand Journal of Economics, 34(2), 329. https://doi.org/10.2307/1593721.

Bakos, Y., \& Brynjolfsson, E. (2000). Bundling and competition on the internet. Marketing Science, 19(1), 63-82. https://doi.org/10.1287/ mksc.19.1.63.15182.

Basuroy, S., Desai, K. K., \& Talukdar, D. (2006). An empirical investigation of signaling in the motion picture industry. Journal of Marketing Research, 43(2), 287-295. https://doi.org/10.1509/jmkr. 43.2.287.

Belk, R. (2014). You are what you can access: Sharing and collaborative consumption online. Journal of Business Research, 67(8), 15951600. https://doi.org/10.1016/j.jbusres.2013.10.001.

Ben-Shahar, O. (2017). Are Uber drivers employees? The answer will shape the sharing economy. Retrieved from https:/www.forbes. com/sites/omribenshahar/2017/11/15/are-uber-drivers-employeesthe-answer-will-shape-the-sharing-economy/\#b9539885e556 . Accessed 12 Mar 2018.

Bikhchandani, S., Hirshleifer, D., \& Welch, I. (1998). Learning from the Behavior of Others: Conformity, Fads, and Informational Cascades. Journal of Economic Perspectives, 12(3);151-170.

Boudreau, K. J., \& Jeppesen, L. B. (2015). Unpaid crowd complementors: The platform network effect mirage. Strategic Management Journal, 36(12), 1761-1777. https://doi.org/10.1002/ smj.2324.

Brynjolfsson, E., Hu, Y., \& Smith, M. D. (2003). Consumer surplus in the digital economy: Estimating the value of increased product variety at online booksellers. Management Science, 49(11), 1580-1596. https://doi.org/10.1287/mnsc.49.11.1580.20580.

Brynjolfsson, E., Hu, Y. J., \& Smith, M. D. (2006). From niches to riches: Anatomy of the long tail. Sloan Management Review, 47(4), 67-71.
Brynjolfsson, E., Hu, Y., \& Smith, M. D. (2010). Research commentary - Long tails vs. superstars: The effect of information technology on product variety and sales concentration patterns. Information Systems Research, 21(4), 736-747. https://doi.org/10.1287/isre. 1100.0325 .

Brynjolfsson, E., Hu, Y. J., \& Simester, D. (2011). Goodbye Pareto principle, hello long tail: The effect of search costs on the concentration of product sales. Management science : journal of the Institute for Operations Research and the Management Sciences, 57(8), 13731386.

Cabral, L., \& Hortaçsu, A. (2010). The dynamics of seller reputation: Evidence from eBay. The Journal of Industrial Economics, 58(1), 54-78. https://doi.org/10.1111/j.1467-6451.2010.00405.x.

Casadesus-Masanell, R., \& Hervas-Drane, A. (2010). Peer-to-peer file sharing and the market for digital information goods. Journal of Economics \& Management Strategy, 19(2), 333-373.

CB Insights. (2018). The Complete List of Unicorn Companies. Retrieved from https://www.cbinsights.com/research-unicorn-companies . Accessed 12 Mar 2018.

Colby, C., \& Bell, K. (2016). The on-demand economy is growing, and not just for the young and wealthy. Harvard Business Review. Retrieved from https://hbr.org/2016/04/the-on-demand-economyis-growing-and-not-just-for-the-young-and-wealthy . Accessed 22 Mar 2018.

Dellarocas, C. (2005). Reputation mechanism Design in Online Trading Environments with pure moral Hazard. Information Systems Research, 16(2), 209-230. https://doi.org/10.1287/isre.1050.0054.

Dreyer, B., Lüdeke-Freund, F., Hamann, R., \& Faccer, K. (2017). Upsides and downsides of the sharing economy: Collaborative consumption business models' stakeholder value impacts and their relationship to context. Technological Forecasting and Social Change, 125, 87-104. https://doi.org/10.1016/j.techfore.2017.03.036.

Dyal-Chand, R. (2015). Regulating sharing: The sharing economy as an alternative capitalist system. Tulane Law Review, 90(2), 241-309.

Einav, L., Farronato, C., \& Levin, J. (2016). Peer-to-peer markets. Annual Review of Economics, 8(1), 615-635. https://doi.org/10.1146/ annurev-economics-080315-015334.

Elberse, A. (2013). Blockbusters: Hit-making, risk-taking, and the big business of entertainment (1. ed.). New York, NY: Holt.

Elberse, A., \& Oberholzer-Gee, F. (2006). Superstars and underdogs: An examination of the long tail phenomenon in video sales (HBS working papers). Cambridge, Mass. Retrieved from http://www.hbs.edu/ faculty/Pages/item.aspx?num=22588 . Accessed 12 May 2017.

Erdem, T., \& Keane, M. P. (1996). Decision-making under uncertainty: Capturing dynamic brand choice processes in turbulent consumer goods markets. Marketing Science, 15(1), 1-20. https://doi.org/10. 1287/mksc.15.1.1.

Fleder, D., \& Hosanagar, K. (2009). Blockbuster Culture's next rise or fall: The impact of recommender systems on sales diversity. Management Science, 55(5), 697-712. https://doi.org/10.1287/ mnsc. 1080.0974 .

Floyd, K., Freling, R., Alhoqail, S., Cho, H. Y., \& Freling, T. (2014). How online product reviews affect retail sales: A meta-analysis. Journal of Retailing, 90(2), 217-232.

Fradkin, A. (2017). Search, matching, and the role of digital marketplace Design in Enabling Trade: Evidence from Airbnb.

Fraiberger, S. P., \& Sundararajan, A. (2015). Peer-to-peer rental Markets in the Sharing Economy. SSRN Electronic Journal. https://doi.org/ $10.2139 /$ ssrn. 2574337.

Hagiu, A., \& Wright, J. (2015). Marketplace or reseller? Management Science, 61(1), 184-203. https://doi.org/10.1287/mnsc.2014.2042.

Heinrichs, H. (2013). Sharing economy: A potential new pathway to sustainability. GAIA, 22(4), 228-231.

Henten, A. H., \& Windekilde, I. M. (2016). Transaction costs and the sharing economy. Info, 18(1), 1-15. https://doi.org/10.1108/info-092015-0044. 
Hinz, O., Eckert, J., \& Skiera, B. (2010). Drivers of the long tail phenomenon: An empirical analysis. Journal of management information systems : JMIS, 27(4), 43-69.

Jann, B. (2016). Estimating Lorenz and concentration curves. Stata Journal, 16(4), 837-866.

Jiang, B., \& Tian, L. (2016). Collaborative consumption: Strategic and economic implications of product sharing. Management Science. https://doi.org/10.1287/mnsc.2016.2647.

Jin, G. Z., \& Kato, A. (2006). Price, quality, and reputation: Evidence from an online field experiment. The Rand Journal of Economics, 37(4), 983-1004. https://doi.org/10.1111/j.1756-2171.2006. tb00067.x.

Kumar, A., Smith, M., \& Telang, R. (2014). Information discovery and the long tail of motion picture content. Management Information Systems Quarterly, 38(4), 1057-1078. https://doi.org/10.25300/ MISQ/2014/38.4.06.

Kyprianou, C. (2017). Creating value from the outside in or inside out: How nascent intermediaries build peer-to-peer marketplaces. Academy of Management Discoveries. https://doi.org/10.5465/ amd.2017.0081.

Laloux, F. (2014). Reinventing organizations: A guide to creating organizations inspired by the next stage of human consciousness (First edition). Brussels, Belgium: Nelson Parker.

Lee, E., Lee, J., \& Lee, J. (2006). Reconsideration of the winner-take-all hypothesis: Complex networks and local Bias. Management Science, 52(12), 1838-1848. https://doi.org/10.1287/mnsc.1060. 0571.

Lee, J., Lee, J.-N., \& Shin, H. (2011). The long tail or the short tail: The category-specific impact of eWOM on sales distribution. Decision Support Systems, 51(3), 466-479. https://doi.org/10.1016/j.dss. 2011.02.011.

Lewis, G. (2011). Asymmetric information, adverse selection and online disclosure: The case of eBay motors. American Economic Review, 101(4), 1535-1546. https://doi.org/10.1257/aer.101.4.1535.

Mair, J., \& Reischauer, G. (2017). Capturing the dynamics of the sharing economy: Institutional research on the plural forms and practices of sharing economy organizations. Technological Forecasting and Social Change, 125, 11-20. https://doi.org/10.1016/j.techfore. 2017.05.023.

Martin, C. J. (2016). The sharing economy: A pathway to sustainability or a nightmarish form of neoliberal capitalism? Ecological Economics, 121, 149-159. https://doi.org/10.1016/j.ecolecon.2015.11.027.

McIntyre, D. P., \& Srinivasan, A. (2017). Networks, platforms, and strategies: Emergent views and next steps. Strategic Management Journal, 38(1), 141-160. https://doi.org/10.1002/smj.2596.

Moreno, A., \& Terwiesch, C. (2014). Doing business with strangers: Reputation in online service marketplaces. Information Systems Research, 25(4), 865-886. https://doi.org/10.1287/isre.2014.0549.

Murillo, D., Buckland, H., \& Val, E. (2017). When the sharing economy becomes neoliberalism on steroids: Unravelling the controversies. Technological Forecasting and Social Change, 125, 66-76. https:// doi.org/10.1016/j.techfore.2017.05.024.

Navis, C., \& Glynn, M. A. (2010). How New Market categories emerge: Temporal dynamics of legitimacy, identity, and entrepreneurship in satellite radio, 1990-2005. Administrative Science Quarterly, 55(3), 439-471. https://doi.org/10.2189/asqu.2010.55.3.439.

Noe, T., \& Parker, G. (2005). Winner take all: Competition, strategy, and the structure of returns in the internet economy. Journal of Economics \& Management Strategy, 14(1), 141-164. https://doi. org/10.1111/j.1430-9134.2005.00037.x.

Oestreicher-Singer, G., \& Sundararajan, A. (2012a). Recommendation networks and the long tail of electronic commerce. MIS Quarterly, 36(1), 65-84.

Oestreicher-Singer, G., \& Sundararajan, A. (2012b). The visible hand?: Demand effects of recommendation networks in electronic markets.
Management Science, 58(11), 1963-1981. https://doi.org/10.1287/ mnsc. 1120.1536.

Parker, G. G., van Alstyne, M., \& Choudary, S. P. (2016). Platform revolution: How networked markets are transforming the economy - and how to make them work for you (first edition).

Pavlou, P. A., \& Gefen, D. (2004). Building effective online marketplaces with institution-based trust. Information Systems Research, 15(1), 37-59. https://doi.org/10.1287/isre.1040.0015.

Podolny, J. M. (1994). Market uncertainty and the social character of economic exchange. Administrative Science Quarterly, 39(3), 458-483. https://doi.org/10.2307/2393299.

Porter, M. E. (2001). Strategy and the internet. Harvard Business Review, 79(3), 62-78, 164.

Puschmann, T., \& Alt, R. (2016). Sharing economy. Business \& Information Systems Engineering, 58(1), 93-99. https://doi.org/10. 1007/s12599-015-0420-2.

Reinstein, D. A., \& Snyder, C. M. (2005). The influence of expert reviews on consumer demand for experience goods: A case study of movie critics. Journal of Industrial Economics, 53(1), 27-51. https://doi. org/10.1111/j.0022-1821.2005.00244.x.

Resnick, P., Zeckhauser, R., Swanson, J., \& Lockwood, K. (2006). The value of reputation on eBay: A controlled experiment. Experimental Economics, 9(2), 79-101. https://doi.org/10.1007/s10683-0064309-2.

Reuber, A. R., \& Fischer, E. (2005). The company you keep: How young firms in different competitive contexts signal reputation through their customers. Entrepreneurship Theory and Practice, 29(1), 5778. https://doi.org/10.1111/j.1540-6520.2005.00069.x.

Rietveld, J., Schilling, M. A., \& Bellavitis, C. (2017). Platform Strategy: Managing Ecosystem Value Through Selective Promotion of Complements. SSRN Electronic Journal. https://doi.org/10.2139/ ssrn.3061424

Rindova, V. P., Williamson, I. O., Petkova, A. P., \& Sever, J. M. (2005). Being good or being known: An empirical examination of the dimensions, antecedents. and Consequences of Organizational Reputation. Academy of Management Journal, 48(6), 1033-1049. https://doi.org/10.2307/20159728.

Rindova, V. P., Petkova, A. P., \& Kotha, S. (2007). Standing out: How new firms in emerging markets build reputation. Strategic Organization, 5(1), 31-70. https://doi.org/10.1177/ 1476127006074389 .

Santos, F. M., \& Eisenhardt, K. M. (2009). Constructing markets and shaping boundaries: Entrepreneurial power in nascent fields. Academy of Management Journal, 52(4), 643-671. https://doi.org/ 10.5465/AMJ.2009.43669892.

Schilling, M. A. (2002). Technology success and failure in winner-takeall markets: The impact of learning orientation, timing, and network externalities. Academy of Management Journal, 45(2), 387-398. https://doi.org/10.2307/3069353.

Schor, J. (2014). Debating the Sharing Economy. Retrieved from http:// www.greattransition.org/publication/debating-the-sharingeconomy. Accessed 25 June 2016.

Shankar, V., \& Bayus, B. L. (2003). Network effects and competition: An empirical analysis of the home video game industry. Strategic Management Journal, 24, 375-384.

Shulman, J. D., Cunha, M., \& Saint Clair, J. K. (2015). Consumer uncertainty and purchase decision reversals: Theory and evidence. Marketing Science, 34(4), 590-605. https://doi.org/10.1287/mksc. 2015.0906 .

Spreitzer, G. M., Cameron, L., \& Garrett, L. (2017). Alternative work arrangements: Two images of the New World of work. Annual Review of Organizational Psychology and Organizational Behavior, 4(1), 473-499. https://doi.org/10.1146/annurevorgpsych-032516-113332. 
Srinivasan, A., \& Venkatraman, N. (2017). Entrepreneurship in digital platforms: A network-centric view. Strategic Entrepreneurship Journal, 45(3), 425-471. https://doi.org/10.1002/sej.1272.

Sun, M., \& Tse, E. (2007). When does the winner take all in two-sided markets? Review of Network Economics, 6(1), 16-40. https://doi. org/10.2202/1446-9022.1108.

Sundararajan, A. (2016). The sharing economy: The end of employment and the rise of crowd-based capitalism.

Tan, T. F., Netessine, S., \& Hitt, L. (2017). Is tom Cruise threatened?: An empirical study of the impact of product variety on demand concentration. Information Systems Research, 28(3), 643-660. https://doi. org/10.1287/isre.2017.0712.

Täuscher, K., \& Laudien, S. M. (2017). Understanding Platform Business Models: A Mixed Methods Study of Marketplaces. European Management Journal, Online before print. https://doi.org/10.1016/ j.emj.2017.06.005.

Tiwana, A. (2015). Evolutionary competition in platform ecosystems. Information Systems Research, 26(2), 266-281. https://doi.org/10. 1287/isre.2015.0573.

Tiwana, A., Konsynski, B., \& Bush, A. A. (2010). Research commentary -Platform evolution: Coevolution of platform architecture, governance, and environmental dynamics. Information Systems Research, 21(4), 675-687. https://doi.org/10.1287/isre.1100.0323.

Townsend, D. M., Hunt, R. A., McMullen, J. S., \& Sarasvathy, S. D. (2018). Uncertainty, knowledge problems, and entrepreneurial action. Academy of Management Annals, 12(2), 659-687. https:// doi.org/10.5465/annals.2016.0109.

Wessel, M., Thies, F., \& Benlian, A. (2017). Competitive Positioning of Complementors on Digital Platforms: Evidence from the Sharing Economy. In Association for Information Systems (Ed.), ICIS 2017 Proceedings .

Ye, S., Gao, G., \& Viswanathan, S. (2014). Strategic behavior in online reputation systems: Evidence from revoking on eBay. Management Information Systems Quarterly, 38(4), 1033-1056. https://doi.org/ $10.2139 /$ ssrn. 1975124

Zentner, A., Smith, M., \& Kaya, C. (2013). How video rental patterns change as consumers move online. Management Science, 59(11), 2622-2634. https://doi.org/10.1287/mnsc.2013.1731.

Zervas, G., Proserpio, D., \& Byers, J. W. (2017). The Rise of the Sharing Economy: Estimating the Impact of Airbnb on the Hotel Industry. Journal of Marketing Research, Research In-Press. https://doi.org/ 10.1509/jmr.15.0204

Zhu, F., \& Iansiti, M. (2012). Entry into platform-based markets. Strategic Management Journal, 33(1), 88-106.

Publisher's note Springer Nature remains neutral with regard to jurisdictional claims in published maps and institutional affiliations. 